\title{
Contributions of Iberian Silvo-Pastoral Landscapes to the Well-Being of Contemporary Society
}

\author{
Diana Surová; Federica Ravera, Nuno Guiomar, Rodrigo Martínez Sastre, Teresa \\ Pinto-Correia
}

\begin{abstract}
Assessments of society's perceptions of rangeland systems offer insights into the motivations, cultural beliefs, and values that can support landscape conservation and the everyday decisions of landowners. Silvo-pastoral landscapes, the grazed oak woodlands known as montado in Portugal and dehesa in Spain, are the main rangelands of southwestern lberia. At the interface of complex interactions between natural processes and human activities, they have potential to deliver multiple services at the ecosystem level. However, the actual rendering of their potential to the well-being of contemporary society has not been comprehensively documented. This paper aims to enrich research perspectives and identify benefits and challenging aspects of silvopastoral landscapes through the lens of society well-being. An integrated socioecological perspective is used to examine one case study in Portugal and one in Spain. To better understand their context, montado and dehesa are assessed relative to other landscape types in the studied areas. A qualitative approach assesses tangible but also intangible aspects. The interviewed stakeholders include members of rural communities, public authorities, land managers, and researchers. Results reveal similar benefits and challenges in montado and dehesa. Interviewees considered them to have numerous sociocultural and environmental benefits. These were mainly regulatory services but also intangible benefits such as cultural identity, aesthetic qualities, and local knowledge. Nevertheless, a rendering of their full potential to society well-being has numerous challenges. These systems were believed to struggle economically, due to the low prices for the goods produced and a high dependence on subsidies. Their environmental vulnerability was also highlighted. Critical challenges for future research and policy interventions are identified for both case studies. Moreover, we encourage the wider application of approaches to rangelands focusing on well-being, as they provide a complement to ecological and economic perspectives that can improve understanding of social-ecological systems.
\end{abstract}

\section{Key Words}

Agriculture; extensive; goods and services; Mediterranean; qualitative assessment, society

DOI: https://doi.org/10.1016/j.rama.2017.12.005

Surová, D., Ravera, F., Guiomar, N., Sastre, R. M., \& Pinto-Correia, T. (2018). Contributions of Iberian Silvo-Pastoral Landscapes to the Well-Being of Contemporary Society. Rangeland Ecology \& Management. 